\title{
Vietnam Outsourcing Risks Management
}

Than Lam, Temple University, USA

\begin{abstract}
The exploratory qualitative research study relied on 32 available literatures from 1983 to 2008 to explore the outsourcing risk to the supply chain management infrastructure within the context of an alliance relationship in which the multinational corporation's manufacturing is outsourced to Vietnam business partners. The paper attempted to define the impact of the Foreign Corrupt Practices Act (FCPA) legislation governing the United States' Multi National Corporations $(M N C)$, roles of culture, ethicality, and social responsibility principles in assessing and mitigating global risks. The paper discussed ethical leadership behavior in risk management. In addition, the paper presented strategies to integrate a relational exchange model and Cost-of-Risk Analysis (CORA) two-step process for cost-benefit evaluation for mitigating global supply chain management risks. The paper also highlighted financial risk management strategies using a net present value (NPV) of at least zero to embark on expenditure streams. Recommendations, summary and conclusion were also presented.
\end{abstract}

Keywords: MNCs; FCPA; global risk strategy; financial risk management; ethical leadership; culture and diversity

\section{INTRODUCTION}

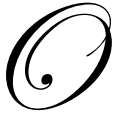

utsourcing was approximately a US \$6 trillion global industry in 2005 (Baron, 2005). The Vietnam markets influence firms to leverage efficiencies and strategies to grow. Outsourcing of non-strategic functions should flatten the organizational structure and heighten the company's strategy focus (Thompson \& Strickland, 1998) and free up resources for new business opportunities (Baron, 2005). However, organizations should be concerned of business outsourcing risks, including the exchange of trade secrets and intellectual capital.

According to Power, Bonifazi, and Desouza (2004), organizations validate the chances of outsourcing windfalls through a risk analysis process before making the decision to move operations off shore. Power et al. identified the following issues:

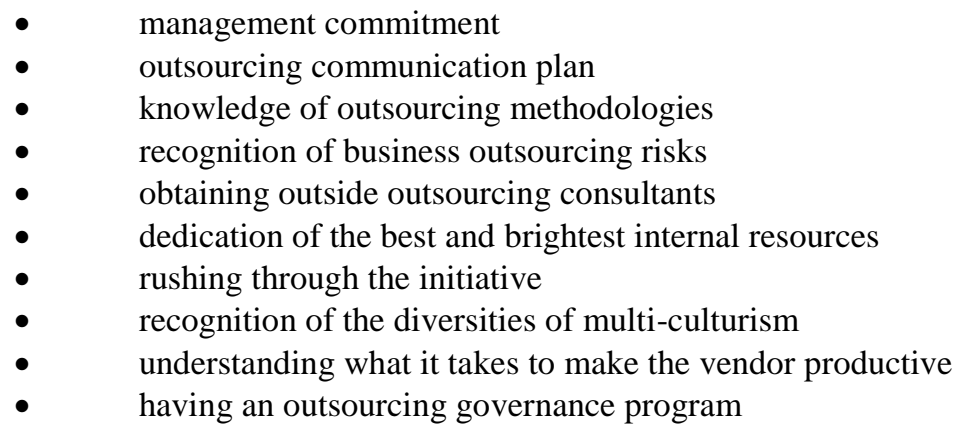

In consideration for a MNC's operational strategy involving the outsourcing of non-strategic functions, this paper explores the risk to the supply chain management infrastructure in Vietnam within the context of an alliance relationship in which the MNC's manufacturing is outsourced to business partners located outside the United States. The rest of the paper is organized according to the main headings of statement of the problem, purpose of the study, research question, research proposition, limitations, review of the literature, strategies, recommendations, and summary and conclusion. 


\section{STATEMENT OF THE PROBLEM}

The American Multi National Corporations "have suffered losses in outsourcing because the infrastructure in the host nation is not up to standard (Ghimire, 2006, p.1)". In addition, Rao, Bhandari, Iqbal, Sinha and Siraj (1999) asserted that cultural differences, language barriers and the lack of adequate infrastructure in the host countries hamper growth. The American MNCs tend to have difficulty managing cultural differences, particularly bribes (MacGregor, 1996), and lost about half of 200 business contracts worth approximately $\$ 40$ billion in 1994 and \$25 billion in 1996 (Across the Board, n.a.).

\section{PURPOSE OF THE STUDY}

Global risk management is the ongoing procedure by which the guiding members of a global business attempt to develop a risk-free plan for the future and define the means for attaining that future. Global risk strategy should provide MNCs with opportunities to incorporate perceived benefits from the risk avoidance implementation methods into the future activities of the organization. The purpose of the exploratory qualitative research study was to provide insights into the outsourcing risk and risk management to the supply chain management infrastructure in Vietnam. The research study provided some indications on why the outsourcing risk occurs, but not on how often it occurs. This research could serve as a base-level handoff to inform future research. The future research may consider investigating how often the outsourcing risk to the supply chain management infrastructure occurs in Vietnam.

\section{RESEARCH QUESTION}

What is the outsourcing risk to the supply chain management infrastructure in Vietnam within the context of an alliance relationship in which the multinational corporation's manufacturing is outsourced to Vietnam business partners?

\section{RESEARCH PROPOSITION}

Vertical integration of outsourcing strategies between a MNC and its suppliers located outside the United States mitigates supply chain management risks. Vertical integration refers to the organization's control of business activities which can be an increase or decrease of product or service distribution (Vidal, 2008).

\section{LIMITATIONS}

This qualitative exploratory research study relied on 32 available literatures from 1983 to 2008 (see references). Because the research was not subjected to scientific rigors, the results of this qualitative exploratory research study are not generalizable to the population at large.

\section{REVIEW OF THE LITERATURE}

\section{Impact of the Foreign Corrupt Practices Act Legislation Governing American MNCs}

Section 3 of the Caux Round Table Principles for Business on the conduct of competitors states that organizations should "refrain from either seeking or participating in questionable pay or favour to secure competitive advantage" (SBE Newsletter, p. 15). In addition, the Organization for Economic Cooperation and Development (OECD) calls for multilateral trade agreements between countries and abhors illicit operations, such as bribery and money laundering while respecting the cultural integrity of countries. The problem, however, is that some organizations and countries around the world offer and receive bribes. Here lies the dilemma for American businesses governed by the FCPA, which prohibits the practice of bribery by American companies doing business abroad. MacGregor (1996) stated "bribery and other conduct that would be illegal in the United States are common in the business" (p.1). In the mean time, American firms are mandated to comply with anti bribery provisions in the FCPA. 
The U.S. Department of Commerce showed American firms lost about half of 200 business contracts in 1996 worth approximately $\$ 25$ billion, which translated to 500,000 American jobs (Across the Board, n.a.). Germany, France, United Kingdom, Japan, and Canada undertook export promotion activities through governmentsponsored trade missions globally. It seems that the trade policies in some of the OECD countries have added up to unfair business practices in relation to the legal constraints imposed on American firms under the FCPA Act.

The American judicial system has increased its bribery investigation of American firms. Mozee (2005) noted that Titan agreed to plead guilty to criminal charges under the FCPA and paid a fine of about $\$ 30$ million, and InVision struck an $\$ 800,000$ deal for a non-prosecution settlement in relation to alleged violations under the FCPA. The FCPA Act, however, indicates some flexibility that allows American firms to offer grease money to officials in countries such as China and Vietnam, where grease payments are considered a traditional way of doing business. The grease payment is to "expedite or secure the performance of a routine governmental action" (FCPA Enforcement, n.a.). The grease money practice adds costs for American firms doing business abroad. Davids (1999) reported that grease payments in China and Vietnam add approximately 3\% to 5\% to the operating costs of companies. Therefore, if an American firm is to negotiate foreign contracts successfully, it is important that due consideration is given to the practice of grease payments in accordance with the FCPA, while at the same time maintaining a strong anti-bribery posture as a part of its ethicality and social responsibility principles.

\section{Role of Culture and Ethicality in Assessing Global Risks}

According to Jones (2004), the best outsourcing mechanism for an organization is one that minimizes transaction cost. The transaction cost is defined as the exchange of resources between organizations located in countries with different cultural values and norms. The degree of transactional cost depends on the degree of discrepancies in the cultural values and ethicalities, and the currency disparities between the outsourced firms.

Geert Hofstede (1980) suggested that countries are culturally distinctive and can be grouped into four categories: (a) power or distance, (b) individualist or collectivist, (c) uncertainty avoidance, and (d) masculinity or femininity (as cited in Volkema and Fleury, 2002). For instance, in the United States, when organizations negotiate and an agreement is reached, it signals the negotiation process is complete and the work begins. On the other hand, in the Middle Eastern countries, when organizations negotiate and an agreement is reached, it signals a serious negotiation begins toward a goal. The cultural predispositions have implications for the way ethical issues are handled in different countries and the development of risk abatement strategies for global organizations. American firms should understand the cultural values of Vietnam to develop ethical standards and social responsibility principles that minimize risk to the organization. There may be laws governing the ethicality of business activities in Vietnam; however, these laws may be loose compared to the rigidly enforced FCPA legislation. To mitigate culturerelated risks, American MNCs should be sensitive to cultural diversity issues and provide relevant training to the Vietnamese employees to minimize transaction costs.

\section{Role of Social Responsibility Principles in Mitigating Global Risks}

Ruggie (2002) asserted that in the global markets, organizations should advance their collective cause by embracing universal values and concerns. Davids (1999) suggested that some of the universal values include the avoidance of illicit and corrupt practices, respecting human rights, and protecting the environment. Nelson (1994) noted that in achieving optimization in the global competitive environment, the rules must be based on the principle that all stakeholders are endowed with specific rights. To this extent, Rawls (1971) espoused a duty of civility, which states "organizations have a duty of civility not...to exploit the inevitable loopholes in social arrangements in order to advance their own interests" (as cited in Nelson, 1994, p. 3).

Global organizations are often constrained by the legal laws in the host countries. Therefore, global organizations must find a way to work around the local laws to ethically project a positive image." Payne, Railborn, and Askvik (1997) suggested international codes of ethical behavior must transcend legal, political, or economic climate established by any country. Payne et al. noted MNCs have both legal and moral obligations to be of good conduct with respect to key constituencies, such as the home government, host governments, general public, individual persons, and the international community. According to Barker and Cobb (2000), a social contract 
between MNCs and host countries should exist "enhancing the welfare of consumers and employees, respecting the rights of people, and minimizing harm to the society" (p. 125).

\section{Ethical Leadership Behavior in Risk Management}

Business ethics are required to derive solutions in a difficult case. According to Donaldson (2000) and Evans and Jewels (2005), three business ethics categories exist - code and compliance to regulate employee behavior, identity and values to present the company characteristics, and social outreach activities to demonstrate the ethical conduct. Donaldson asserted that the code and compliance category seems to be the most effective approach for organizations to deploy and ethical program. A code of ethics has to be enforced. To be effective, leaders should choose the approach that appropriates and aligns with their organizations' cultures, structures, and processes. Veit (2001) noted that leaders have to make decisions between right and wrong and focus on social responsibilities, even when they face a loss of profits. Wells posited that three ethical choices should be made:

1. $\quad$ an end-based choice of the "greatest good for greatest number" (p. 3)

2. a rule-based choice of a "universal standard for everyone" (p. 3)

3. a care-based choice of "whatever you'd like others to do to you" (p. 3)

An ethical decision must be good for the majority, accepted by everyone, and lead to behavior corresponding to what one would want others to do for him or her. These choices should be weighted or combined for the best possible decision outcome.

\section{STRATEGIES}

\section{Model for Mitigating Supply Chain Management Risks in Partnership Alliances}

Morgan and Hunt (1994) stated that no firm can survive alone in today's global economy, particularly given the fast changing environment. Organizations have sought increasingly to achieve sustainability through value creation derived from collaborative partnerships and networks. According to Morgan and Hunt (1994), synergies in networking and partnering can only be created and maintained through relational exchanges, trust, and commitment in the relationship.

Morgan and Hunt (1994) presented a model of the relational exchanges involving a firm and its partners, suppliers, competitors, non-profit organizations, governments, buyers, and its own internal business units, employees, and functional departments. To mitigate risks related to network environments, MNCs should embrace a multicultural and diversified workforce, and develop effective working relationships with partners, suppliers, and local governments to optimize operations. A structured contract should be written for employees and union partners. Senior executives should support and be involved in the outsourced relationships.

MNCs should treat their outsourced vendors as company partners, and build partner-management charter, processes and governance structure. A team with members from partners should be formed to oversee partners' performances and to ensure that operational coordination and facilitation between partners are carried out adequately. Periodic and formal meeting with senior management should be established to resolve emerging issues and to ensure MNCs and partners' objectives are followed and aligned. In maintaining strategic objectives, MNCs and outsourced partners should form teams to research for new opportunities. Otherwise, outsourcing becomes solely process efficiency efforts. In addition, MNCs should embrace partners' cultures and exchange staffs and ideas to find new ways to improve business process, thus reducing risks.

Berenbeim (2000) stated, "Corporate codes establish uniform business conduct standards and provide the principles for self-regulation" (p.1). Therefore, MNCs and outsourced partners should establish ethical codes and social responsibility standards for domestic and international operations. Furthermore, the corporate codes should be disseminated, implemented, monitored and enforced for effectiveness. 
Recent scandals with Enron, WorldCom, and Titan suggested that corporate ethical codes did not seem to be having much success. Berenbeim (2000) argued that in order for corporate codes to be effective, the MNC and its outsourced partners should introduce codes in an environment that can be trusted. Corporate leaders should support and monitor their codes to deter corruption.

The outsourced partners should be required to receive ethics training and to implement the codes of ethics. In regards to MNCs intellectual property, the outsourced partners should receive security training and to sign nondisclosure agreements. The policy should specify who should be responsible to direct, implement and enforce the procedures and standards that govern supply chain management requirements for "service providers, customers, and business associates" (The World Bank Technology Checklist, 2004, p.12).

To minimize the risk of supply chain and inventory from being interrupted, security of communication systems, Internet access, as well as physical infrastructure, must be secured and protected. Procedures, physical access policy, disaster recovery, and a contingency plan that determine "the security impact of linking new/external systems to the organization's infrastructure" and "security service level and operational readiness requirements" must be maintained (The World Bank Technology Checklist, 2004, p.11 \& p.12).

From a legal standpoint, the United States, international, and local laws must be respected and complied with by MNCs and the outsourced partners. In addition, the outsourcing policies should address "due diligence requirements", "legal requirements", "existence [and] adequacy of insurance to protect against financial losses due to third-party negligence", internal audits and its frequency, "background checks", "privacy policy", "incentives and financial repercussions for instances of service outages". Most importantly, "consequences for non-compliance with policies" should be documented and enforced (The World Bank Technology Checklist, 2004, p.12 \& p.13).

Meyer and Kolb (2004) suggested that outsourcing should involve four elements:

1. Strategy

2. Process

3. Technology

4. Communication

To ensure that value is derived from risk abatement strategies, answers to the following questions should be found as a prelude to reaching outsourcing decisions; for example, what value the outsourced partner provides as compared to the company's own staff, and what country and where should the staff be located. Regarding costbenefit analysis for purposes of ensuring positive Return on Investment (ROI), issues such as billing rate, geographical distances, time-zone differences, and communication method should be integrated into the analysis of outsourcing risks and cost considerations. One of the popular analytical models is Cost-of-Risk Analysis (CORA), which could be applied for purposes of the cost-benefits and ROI analyses. CORA should be used to provide a convenient context within which MNCs could organize, collect, store, validate, and collate the data that describe the risks and loss exposures of the organization. Then the sophisticated algorithms built into CORA should be used to construct a Quantitative Risk Model. Specifically, CORA could be used to calculate Single Occurrence Loss (SOL) and Annualized Loss Expectancy (ALE), and the results could be displayed in tabular and graphical forms. In the final analysis, MNCs can then apply the results derived from CORA for purposes of performing Risk Management Evaluations aimed at identifying the optimum package of risk management measures (CORA, n.a.)

\section{Financial Risk Management}

The MNCs have an exchange rate risk and country risk. The process of managing financial activities requires an analysis of the financial and economic variables that could impact MNCs. Anderson and Narus (1991) provided a framework for the development of partnerships between the firm, suppliers, and customers. Anderson and Narus suggested that a framework should be broad enough to accommodate any shifts imposed by the environment on the partnership characteristics. Anderson and Narus defined partnership as a process where a firm, supplier, and customers have "social, economic, service, and technical ties with the intent of increasing their value" (p.96). Financial imperatives and the matrices for evaluating organizational performance are important to the 
profitability and survivability of organizations.

According to Madura (2003) when MNCs enter international markets, the motivations include attracting new sources of demand, entering profitable markets, benefiting from economies of scale, utilizing foreign factors of production, and utilizing foreign technology. Madura postulated that the impact of international opportunities on a MNC's value is a function of the expected cash flow to be received in period $t$, expected exchange rate of conversion at the end of period $t$, weighted average cost of capital, number of currencies involved, and number of periods in relation to the valuation exercise. Badiru and Pulat (1994) stated the interest rate used in performing is set equal to the minimum attractive rate of return (MARR). In relation to this type of analysis, Badiru and Pulat defined internal rate of return for a cash flow as "the interest rate that equates the future worth at time $n$ or present worth at time 0 of cash flow to zero" (p.349). A positive internal rate of return indicates positive cash flow and vice versa. The cost benefit ratio of a cash flow, in this respect, is represented by "the ratio of the present worth of benefits to the present worth of costs" (p.351). A ratio of one indicates a breakeven situation.

In terms of financial viability in international operations, Mandura (2003) suggested a capital budgeting process that takes into consideration factors, such as initial investment, consumer demand, price, variable and fixed costs, project life time, salvage value, restrictions on fund transfers, currency exchange rates, tax laws, and rate of return. Madura recommended financial analysis using a net present value (NPV) of at least zero in order to embark on expenditure streams. The formula for calculating net present value is displayed below:

$\mathrm{NPV}=-\mathrm{IO}+$ Zigma, $\mathrm{n}($ supra $), \mathrm{t}=1(\mathrm{sub}) \times \mathrm{CF}, \mathrm{t}($ sub $) / \mathrm{l}=\mathrm{K}, \mathrm{t}($ supra $)+$ $\mathrm{SV}, \mathrm{n}(\mathrm{sub}) / \mathrm{l}+\mathrm{k}, \mathrm{n}$ (supra).

where,

$\mathrm{IO}=$ initial outlay (investment)

$\mathrm{CF}, \mathrm{t}(\mathrm{sub})=$ cash flow in period $\mathrm{t}$

$\mathrm{SV}, \mathrm{n}(\mathrm{sub})=$ salvage value

$\mathrm{k}=$ required rate of return

$\mathrm{n}=$ life time of project (number of periods) (Mandura, p. 420)

The global markets present uncertainties related to the present value of commodities and services and, therefore, their impact on ROI. Some of the financial uncertainties in the return of investments accrue from differences in the restrictions on fund transfers, currency exchange rates, and tax laws specific to different countries. Companies can mitigate potential losses from financial uncertainties by applying approaches such as hedging, futures, forward contracts, call and put options (Aggarwal and Grosse, 2000). Aggarwal and Grosse noted that rather than a zero-sum game, hedging can be viewed as a positive-sum game, thereby adding value to organizations given that markets are not perfect.

\section{RECOMMENDATIONS}

The emphasis is on risk abatement strategies in the supply chain management infrastructure aimed at enhancing critical success factors in the partnership alliance with suppliers. According to Alazmi and Zairi (2003), critical success factors are described as "the areas where things must go right for a business to flourish....and what the organization must accomplish to achieve the mission by examination and categorization of impacts...that must go well to ensure success for a manager and/or organization" (p. 199). To this extent, the Board of Directors and senior management team should address the impact of international compliance issues governing MNC's, the culture and ethical global risks, corporate social responsibility global risks, ethical decision-making in risk management, and corporate governance.

The Board of Directors should focus on risk factors related to across-border partnership alliances specific to outsourcing. The following risk abatement measures should be instituted: 
1. a formal agreement incorporating language and policy guiding a multicultural and/or diverse workforce and working relationship management guidelines between partners

2. a structured charter incorporating partner-management, processes and governance

3. guidance in ways to monitor, facilitate, coordinate, and measure performance in partnership arrangements

4. a schedule of periodic meetings between senior management to address and resolve enterprise wide risk and to ensure risk mitigating and abating objectives are followed

5. guidance to create a team between partners to identify new opportunities to increase equitable competitiveness

6. universal and standardized ethical codes of conduct and social responsibilities between partnerships in a domestic and cross border landscape

7. guidance for cross-partnership labor exchange to improve processes

8. non-disclosure agreements and security training with regard to intellectual capital

9. a business continuity plan for technological architecture and infrastructure.

A test run of data should be displayed in terms of ROI and cost benefit analysis in the context of Single Occurrence Loss and Annual Loss Expectancy exhibited by tables and graphs. The idea should be to provide examples of the net present benefits in relation to the revenue stream generated based on the cost of the risk abatement strategies instituted.

\section{SUMMARY AND CONCLUSIONS}

Vietnam has become a reality for most organizations seeking to expand their capabilities to achieve sustainability. The paper revealed that globalization initiatives are not without risks. Thus, MNCs continue to seek risk-mitigation strategies associated with cross-border international business relationships. In addition, MNCs should focus on adoption and implementation of risk-mitigation strategies related to the outsourcing relationships between partners.

Through the outsourcing of non-crucial support activities, MNCs could increase their competitive responsiveness through value chain enhancements, thereby freeing up capital resources needed to develop new business opportunities. The paper provided recommendations to MNCs with respect to risk abatement strategies, cultural impact of host countries, approach to developing appropriate security apparatus, evaluating ethicality and value systems of host countries and outsourced organizations, developing social responsibility principles, evaluating risks related to knowledge and technology exchanges, and developing hedging strategies for mitigating risks associated with international financial transactions. In spite of the limitation to the present study, which had to do with the over reliance on information gathered, which were not subjected to scientific rigors, the findings have contributed to a better understanding of risk-mitigation strategies between international business partners in an outsourcing relationship. Further research would be needed to support the generalizability of the present findings.

\section{AUTHOR INFORMATION}

Than Lam has twenty-five years of experience in systems and software engineering, information systems, and business development which focus on innovation and Earned Value Management leading multiple international and US programs. Dr. Lam is Adjunct Assistant Professor at Temple University Fox School of Business MIS and Six Sigma Black Belt and Lead Member Engineering Staff at Lockheed Martin Mission Systems and Sensors (MS2) with a research focus on Business-IT Fusion, Systems Modeling Language, Unified Modeling Language and Engineering Collaborative applications. His educational accomplishments include Doctor of Business Administration in MIS from University of Phoenix, MBA and Master of Engineering Science in Computer Engineering from Pennsylvania State University, and Bachelor of Engineering in Electrical Engineering from State University of New York (SUNY) Maritime College.

\section{REFERENCES}

1. Aggarwal, R. and Grosse, R.E. (2000). Global financial strategy for the twenty-first century. Thunderbird on global business strategy (Ed. Grosse, R.E.). New York, N.Y.: John Wiley \& Sons 
2. Alazmi, M., Zairi, M. (2003). Knowledge Management Critical Success Factors. Total Quality Management. Volume 14, Issue 2.

3. Anderson, J.C. and Narus, J.A. (1991). Partnering as a focused market strategy. California Management Review. Vol. 33, Issue 3.

4. Badiru, A.B. and Pulat, P.S. (1994). Comprehensive project management: Integrating optimization models, management principles, and computers. Englewood Cliffs, N.J.: Prentice Hall.

5. Barker, T.S. and Cobb, S.L. (2000). A survey of ethics and cultural dimensions of MNCs. Competitive Review, Vol 10, Issue 2.

6. Baron, A. (2005). The People Impact of Outsourcing. Strategic Communication Management. Volume 9, Issue 1, p. 13 (1). Retrieved on March 12, 2005 from the University of Phoenix Apollo Library EBSCO Host Database.

7. Berenbeim, R. (2000). Global ethics. Executive Excellence, Vol. 17, Issue 5.CORA (2005). Helping you to manage risks. International Security Technology, Inc. Retrieved March 12, 2005 from http://www.istusa.com/aboutcora.htm

8. Davids, M. (1999). Global standards, local problems. The Journal of Business Strategy, Vol.20, Issue 1.

9. Donaldson, T. (2000, January 13). Adding corporate ethics to the bottom line. Financial Times, 1-3. Retrieved February 17, 2006, from http://lgst.wharton.upenn.edu

10. Evans, N., \& Jewels, T. (2005). Ethical IT behavior as a function of environment: Issues in informing science and information technology. Retrieved January 23, 2006, from http://proceedings.informingscience.org

11. Ghimire, B. (2006, July 06). The outsourcing industry. AC Associated Content, 1-8. Retrieved August 5, 2009, from http://www.associatedcontent.com/article/41369/the_outsourcing_industry_pg2.html?cat=1

12. Jones, G.R. (2004). Organizational theory, design, and change: Text and cases, Fourth Edition. New Delhi, India: Pearson Educational Publication.

13. MacGregor, R.W. (1996). Promoting a world ethical standard. Nation's Business, Vol.84, Issue 4

14. Madura, J. (2003). International financial management. Mason, $\mathrm{OH}$ : Thompson

15. Magretta, J. (1998). The power of virtual integration: an interview with dell computer's Michael Dell. Harvard Business Review, 76(2).

16. Meyer, B., \& Kolb, P. (2004). Successful software outsourcing and offshoring. Retrieved 3/12/05 at http://se.inf.ethz.ch/teaching/ws2004/0273/slides/outsourcing-eth-01.pdf

17. Morgan, R., \& Hunt, S. (1994). The commitment-trust theory of relationship marketing. Journal of Marketing, 58, 20-38.

18. Mozee, C. (2005). Feds cast corporate dragnet abroad: Stepping up scrutiny triggers self-audits, ethical review, MarketWatch, Feb. 2, 2005

19. (n.a.). Caux Round Table Principles For Business. SBE Newsletter, Vol. 6, Issue 1

20. (n.a.). FCPA Enforcement. Retrieved August 9, 2009 fromhttp://www.fcpaenforcement.com/explained/explained.asp

21. (n.a.). Foreign practices. Across The Board, Vol. 33, Issue 9.

22. (n.a.). The World Bank Technology Risk Checklist 7.3. World Bank Integrator Unit and TRE Security Team Collaboration. Retrieved March 3, 2005 from http://www.infragard.net/library/pdfs/technologyrisklist.pdf

23. Nelson, J. (1994). Business ethics in a competitive market. Journal of Business Ethics, Vol. 13, Issue 9.

24. Papadakis, I. (2003). On the sensitivity of configure-to-order supply chains for personal computers after component market disruptions. International Journal of Physical Distribution \& Logistics Management. Bradford. 2003. Vol. 33, Iss. 9/10

25. Payne, D., Railborn, C. and Askvik, J. (1997). A global code of business ethics. Journal of Business Ethics. Vol. 16, Issue 16.

26. Power, M., Bonifazi, C., Desouza, K. (2004). The Ten Outsourcing Traps to Avoid. Journal of Business Strategy. Volume 25, Issue 2, p. 37 (6).

27. Rao, M., Bhandari, S., Iqbal, S., Sinha, A., \& Siraj, W. (1999, April). "Struggling with the digital divide, Internet infrastructure, policies and regulations," Retrieved July 1, 2005, from http://www.sasianet.org

28. Ruggie, J.G. (2002). The theory and practice of learning networks: Corporate social responsibility and the global compact. The Journal of Corporate Citizenship, Vol. 27, Issue 10.

29. Veit, L. (2001). Ethical matters. Credit Union Management, 24(6), 18-20. 
30. Vidal, D. (2008). Vertical integration. 12 Manage: The Executive Track. Retrieved on June 27, 2008 at http://www.12manage.com/methods_vertical_integration.html

31. Volkema, R.J. and Fleury, M. T. L. (2002). Alternative negotiating conditions and the choice of negotiation tactics: A cross-cultural comparison. Journal of Business Ethics, Vol. 36, Issue 4 
NOTES 